A human nerve cell

(neuron) derived

from an induced

pluripotent stem cell.

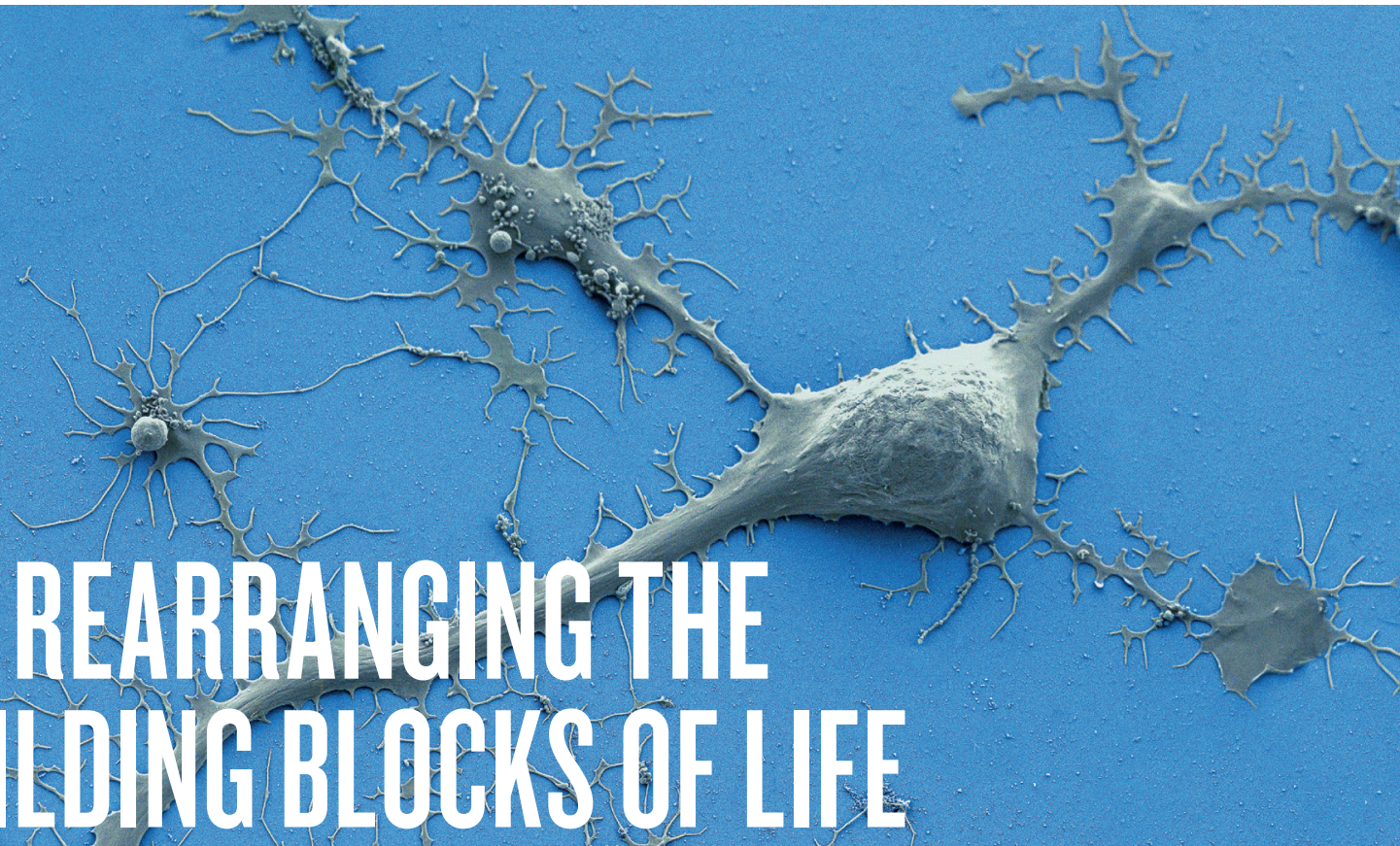

his is the century in which biomedical science could transform the ideal of healthy human life.

Consider the progress of the past few years. Breakthroughs in cancer immunotherapy have achieved astonishing transformations in patients whose death was presumed imminent. Pre-exposure prophylaxis for HIV is showing almost $100 \%$ effectiveness in preventing transmission of the disease. Revolutionary geneediting technologies are challenging the basis of congenital disease, and stem-cell research is delivering some of the first products to market.

"I used to say, maybe in my lifetime we'll see stem cells hit the clinic for Parkinson's disease," says Clare Parish, a stem-cell neurobiologist at the Florey Institute of Neuroscience and Mental Health in Melbourne, Australia. "Now I think in the next five years we'll have them in the clinic."

Globally, more than US $\$ 240$ billion is invested in health $\mathrm{R} \& \mathrm{D}$ each year. The unprecedented pace of innovation, though, has done nothing to ease the problems of equity, efficiency and ethics that cloud the vision of longer, healthier life for all.

In the United States, which spends more on biomedical research than any other nation, a wave of concern has risen over the threatened loss of its lead in global research to China. University of Michigan researchers, for example, warned in a 2017 JCI Insight article: “The implications are immense, including economic and societal in addition to security and global ramifications."

The researchers predicted that China's funding would overtake that of the US in 2022. According to the US Congressional Research Office, the purchasing power of funding for the National Institutes of Health (NIH), the US's pre-eminent biomedical research body which also distributes funding to other institutions, peaked in 2003 and then declined fairly steadily until 2015. Despite gains since, the inflationadjusted projected funding level for 2020 will be $22.4 \%$ lower than in 2003 .

China's remarkable progress has narrowed the gap in research output, yet the US retains a formidable lead, with its fractional count in the Nature Index of 8,422 in 2018 more than four times that of China's at 2037.

There are warnings that a generation of brilliant minds is being lost to other endeavours. Jeffrey Bluestone, an endocrinologist at the University of California, San Francisco, along with David Beier, a health-care policy adviser at Bay City Capital, and Laurie Glimcher, a Harvard Medical School cancer specialist, called for "aggressive structural and cultural changes to the federal research enterprise" in a 2018 statnews.com article.

As scientists gain new ability to manipulate the building blocks of life, ethical issues loom larger. This was exemplified in late 2018 when a geneticist in China, He Jiankui, introduced the first ever gene-edited babies. The researcher's claims have yet to be verified, but a government investigation stated that he violated state law in pursuit of "personal fame and fortune", and he has been sacked from his university. 


\section{CHINA CHASES THE US}

The US has a commanding lead in biomedical sciences globally in terms of both funding and high-quality research output, despite declines in each.

China's high-quality biomedical sciences research output, measured by fractional count (FC) in the Nature Index, escalated by $141.2 \%$ from 2012 to 2018 , eclipsing other countries' modest gains.
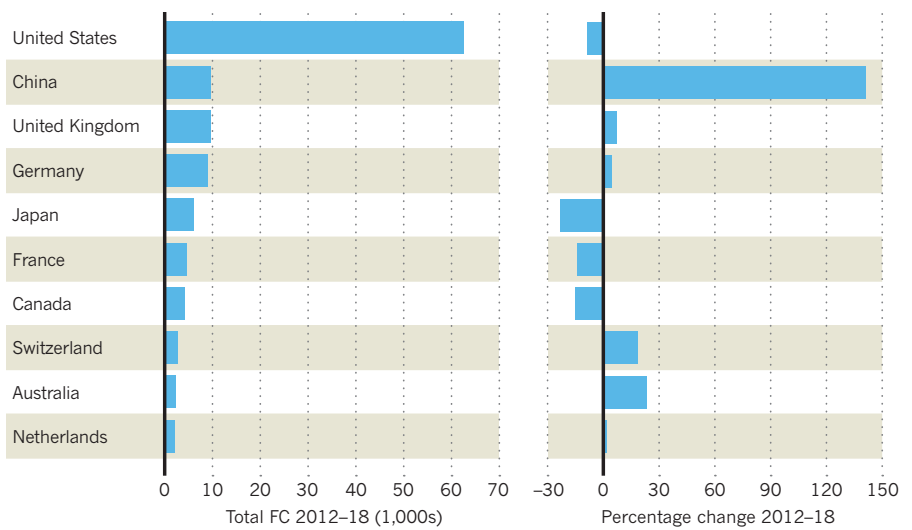

Percentage change 2012-18
Funding for biomedical sciences research and average grant sizes from select major funders, 2008-18. Comparable figures for China are not available.
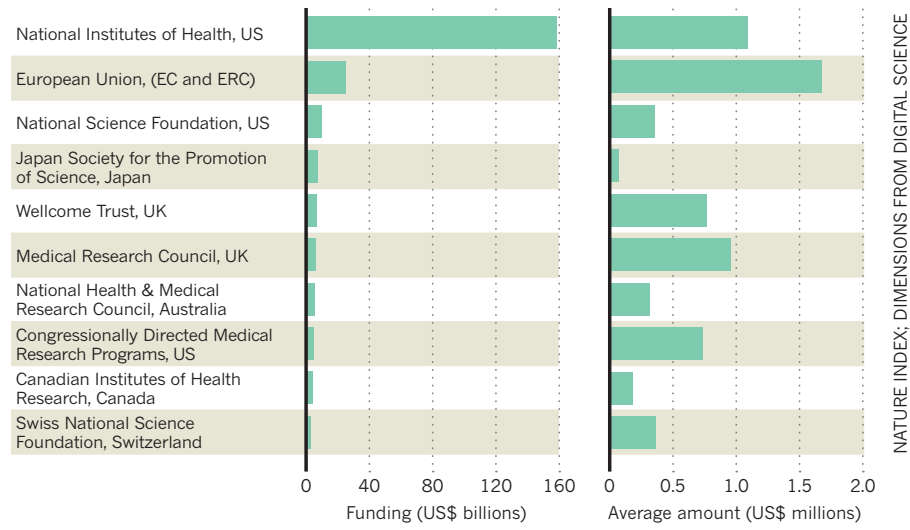

Wilfried Ellmeier, professor of immunobiology at the Medical University of Vienna and president-elect of the Biomedical Alliance in Europe, believes it is accepted that "CRISPRCas9 technology should be applied for treating diseases, but should not interfere with the germ-line", which means it should not be used to make permanent changes to the genome that could be passed on to future generations. The law backs this up: implanting genetically engineered human embryos is prohibited in most of Europe, the US, and China. The World Health Organization (WHO) created a panel to advise on an international framework governing the use of gene-editing technologies.

\section{FORMIDABLE OBSTACLES}

Solving the problem of antimicrobial resistance is among biomedical research's most urgent challenges. The WHO cites resistance to tuberculosis drugs, for example, as a "formidable obstacle" to fighting a disease that kills 1.6 million every year. Yet few large pharmaceutical companies are investing in antibiotics. A 2019 report from Pew found that there are 42 new antibiotics in development, with just 13 in phase III trials.

The withdrawal of many major companies, such as Novartis in 2018 and AstraZeneca in 2016, from the search for new antibiotics means much of the early R\&D is being done by smaller biotechnology companies. "A lot of these organizations have been able to fund their discovery, preclinical and early-phase development, to some extent, with sufficient capita, but they're not well situated for latestage development and commercialization," says Wes Kim, pharmaceuticals scientist in Pew's antibiotic resistance project.

As many companies abandon the search for replacement antibiotics, cellular and gene therapies are proving attractive targets. US biotechnology giant Amgen, and the University of Iceland had the biggest corporate-academic collaboration by article count in biomedical sciences in the journals tracked by the Nature Index in past three years. With the purchase of Icelandic genetics company, deCODE Genetics for US $\$ 415$ million in 2012, Amgen is working with University of Iceland academics on genome-wide association studies, which investigate the human genome for small genetic variations that could indicate a higher risk for certain diseases. The next biggest corporateacademic collaboration saw Novartis and Harvard University team up to develop cancer immunotherapies.

Although cancer and heart disease are the biggest killers in high-income nations, the health burden in low-income nations is different. There, infectious and parasitic diseases are by far the most common threat. Yet only $4 \%$ of all new therapeutic products and $1 \%$ of new medicines approved between 2000 and 2011 were aimed at such neglected diseases, even though they account for $11 \%$ of global disease.

The Drugs for Neglected Diseases Initiative, a not-forprofit drug $\mathrm{R} \& \mathrm{D}$ organization, is bringing together academia, public health institutes, and the biotechnology and pharmaceutical industries to combat diseases such as sleeping sickness, malaria and paediatric HIV, where investment in research is sorely lacking.

But no amount of investment will cure a disease until the science stacks up. Alzheimer's disease, which affects almost 50 million people globally, is a case in point. Since the US Congress recognized it as a major threat four years ago, there has been a major infusion of funding to the NIH for research into Alzheimer's and related dementias, bringing the total to US $\$ 2.3$ billion in 2019. A plethora of failed trials of treatments have targeted the amyloid cascade - the build-up of aberrant amyloid protein in the brain. Most recently, the high-profile failure of aducanumab, the anti-amyloid drug, to show significant clinical benefit has prompted its manufacturers to cancel phase III trials.

The problem is that a lot of leaders in the field have built their careers around amyloids, but no strong contenders have emerged to replace amyloids as the main target for Alzheimer's treatments, "and the advances in terms of therapy are based on ideas from the late 1970s", says George Perry of the Brain Health Consortium at the University of Texas at San Antonio, and editor-in-chief of the Journal of Alzheimer's Disease.

Artificial intelligence (AI) could play a key role in unravelling Alzheimer's, antimicrobial resistance, and other colossal challenges. Pharmaceutical firms have started buying up tech companies that specialize in $\mathrm{AI}$ in the hope of speeding up discovery. In 2019, Swiss multinational health-care company Roche entered a US\$65-million partnership with AI-driven drug-discovery company Exscientia. The Accelerating Therapeutics for Opportunities in Medicine (ATOM) consortium, a US public-private partnership, including the health-care company GSK and the US Department of Energy, was created in 2016 with the same intent.

Faster, more accurate, and more detailed analysis of data than has ever been possible, powered by machines performing analytical feats of unprecedented scale, will quicken the pace of biomedical discovery in other areas. AI is being applied to predict potential toxicity and the solubility of molecules, and is even generating new molecules from scratch.

No matter the successes and failures ahead, biomedical research will continue to carry the hope of a better life for all. 